\title{
"O ESSENCIAL É INVISÍVEL AOS OLHOS": PERCEPÇÕES ACERCA DA INTERCULTURALIDADE E ETNOMATEMÁTICA NO ATENDIMENTO À INFÂNCIA INDÍGENA
}

\author{
FERNANDO SCHLINDWEIN SANTINO ${ }^{1}$ \\ UNESP, BRASIL \\ http://orcid.org/0000-0002-7757-8826
}

KLINGER TEODORO CIRÍACO

UFSCar, BRASIL

http://orcid.org/0000-0003-1694-851X

\begin{abstract}
RESUMO: Relatamos dados de uma investigação cujo objeto for a ações desenvolvidas no âmbito de um projeto de extensão promovido pela Universidade Federal de Mato Grosso do Sul - UFMS, Campus Naviraí. Trata-se do curso Infância, Interculturalidade e Etnomatemática na Educação Infantil: o atendimento à criança indígena, em que o público-alvo foi professoras que tinham crianças de duas etnias (Guarani e Kaiowá) matriculadas nas instituições em que trabalhavam. Objetivou-se compreender impactos deste à promoção de práticas pedagógicas que valorizem a Interculturalidade na perspectiva da Etnomatemática desde a infância. O referencial teórico contempla documentos e produções sobre as temáticas-chaves da discussão em uma ampla relação com a cultura indigena. A metodologia se enquadra na descrição e análise prévia de respostas ao questionário desenvolvido no encontro inicial. As questões analisadas apontam para a existência de algumas barreiras para que o atendimento à infância indígena se faça de forma mais inclusiva, uma vez que, as docentes declararam, por exemplo, a lingua nativa [Guarani] como fator determinante às dificuldades no processo de exploração das noções matemáticas, justamente por não compreenderem os termos adotados pelas crianças.
\end{abstract}

PALAVRAS-CHAVE: Interculturalidade, etnomatemática, infância indigena, formação de professores.

ABSTRACT: We report data from an investigation whose object was actions developed within the scope of an extension project promoted by the Federal University of Mato Grosso do Sul UFMS, Campus Naviraí. This is the course Childhood, Interculturality and Ethnomathematics in Early Childhood Education: assisting indigenous children, in which the target audience was teachers who had children of two ethnic groups (Guarani and Kaiowá) enrolled in the institutions where they worked. The objective was to understand its impacts to the promotion of pedagogical practices that value Interculturality in the perspective of Ethnomathematics since childhood. The theoretical framework includes documents and productions on the key themes of the discussion in a broad relationship with indigenous culture. The methodology fits in the description and previous analysis of responses to the questionnaire developed in the initial meeting. The analyzed issues point to the existence of some barriers for the assistance to indigenous children to be done in a more inclusive way, since, the teachers declared, for example, the native language [Guarani] as a

\footnotetext{
${ }^{1}$ Mestrando em Educação pela Universidade Estadual Paulista "Júlio de Mesquita Filho" - Faculdade de Ciências e Tecnologia, UNESP/FCT, Presidente Prudente-SP. E-mail: fernando.santino@unesp.br

${ }^{2}$ Professor Adjunto do Departamento de Teorias e Práticas Pedagógicas - DTPP - do Centro de Educação e Ciências Humanas - CECH - da Universidade Federal de São Carlos - UFSCar, São Carlos-SP. Docente Permanente do Programa de Pós-graduação em Educação Matemática da Universidade Federal de Mato Grosso do Sul - UFMS, Campo Grande-MS. E-mail: ciriacoklinger@gmail.com
} 
Espaço Ameríndio

determining factor to the difficulties in the exploration process mathematical notions, precisely because they do not understand the terms adopted by children.

KEYWORDS: Interculturality, ethnomathematics, indigenous childhood, teacher training. 
Espaço Ameríndio

\section{Introdução}

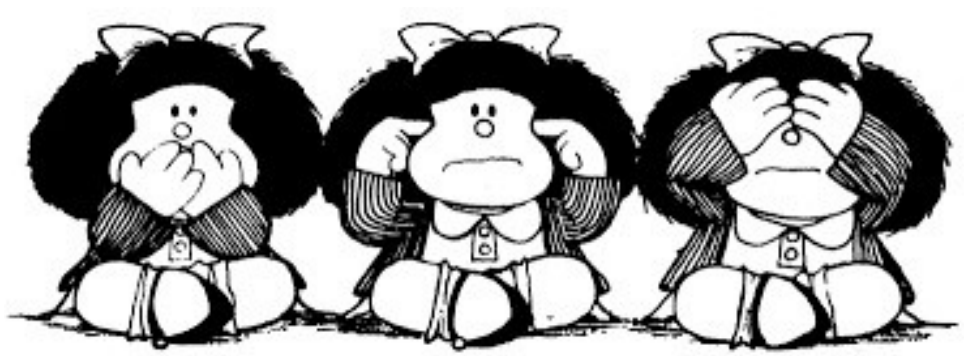

Fonte: https://valterbitencourtjuniorpoetaeescritor.wordpress.com/2018/10/04/e-necessario-

conhecer-a-historia-para-nao-cometer-os-mesmos-erros-do-passado/ ${ }^{3}$

Desde $1^{\circ}$ de janeiro de 2019, com o processo de posse de um candidato de extrema direta à Presidência da República, temos acompanhado, na mídia e em decretos federais, diversas mudanças no contexto da sociedade brasileira, alterações históricas, até então nunca vistas, que implicam fortes desigualdade frente aos Direitos Humanos com relação à temática das comunidades indígenas nas pautas dos organismos governamentais. É neste contexto histórico-político-social que escrevemos, reivindicando a defesa dos direitos das crianças pertencentes às etnias que poderão estar, tão logo, fortemente ameaçadas, como temos acompanhado nos últimos meses.

Discutir a Educação e a Educação Infantil, em defesa da criança indígena, é, para nós, pressuposto basilar de ações que se intitularam interculturais, uma vez que tal conceito pressupõe a coexistência de duas ou mais culturas em movimento de interação de modo sinérgico e horizontal, sem supervalorização de uma em detrimento da outra. Para este fim, é preciso que os grupos étnicos, por exemplo, estabilizem instância de integração e convivência coletiva, como é o caso das instituições de ensino, pois é na escola que as crianças e as culturas se encontram. Ao reportar tais reflexões, não podemos nos eximir do falar, ouvir e enxergar as múltiplas culturas infantis que coexistem na instituição de Educação Infantil, particularmente naquelas que se encontram em um Estado que possui a segunda maior população indígena do Brasil, como é o caso de Mato Grosso do Sul.

Desse modo, o presente artigo coloca como propósito apresentar e dialogar com dados parciais de uma pesquisa, desenvolvida junto à Fundação Universidade Federal de Mato Grosso do Sul (UFMS, Campus Naviraí), cuja a temática central de investigação foi a Interculturalidade e Etnomatemática na Educação Infantil a partir de experiências de um grupo de professoras, as quais têm em suas respectivas turmas crianças indígenas regularmente matriculadas.

Os dados foram coligidos no âmbito de uma ação de extensão, coordenada pelo Prof. Dr. Klinger Teodoro Ciríaco, no ano de 2018, intitulada Infância, Interculturalidade e Etnomatemática na Educação

\footnotetext{
${ }^{3}$ Acesso em: 04, maio 2020.

SANTINO, Fernando Schlindwein; CIRÍACO, Klinger Teodoro. "O essencial é invisível aos olhos": percepções acerca da interculturalidade e etnomatemática no atendimento à infância indígena. Espaço Ameríndio, Porto Alegre, v. 15, n. 1, p. 113-133, jan./abr. 2021.
} 
Infantil: o atendimento à criança indígen $a^{4}$. Temos a pretensão de discutir no texto que segue algumas das reflexões sobre o que dizem as docentes quando o assunto envolve os termos-chaves do direcionamento da ação formativa realizada que possibilitaram, via aplicação de questionário diagnóstico, perceber o ideário pedagógico, bem como as dificuldades iniciais de estruturação de práticas pedagógicas promotoras de uma cultura híbrida, sendo esta compreendida aqui como processos que permitem, como é o caso da interação entre as crianças, compartilhamentos de experiências culturais (costumes e hábitos).

\section{Referencial teórico}

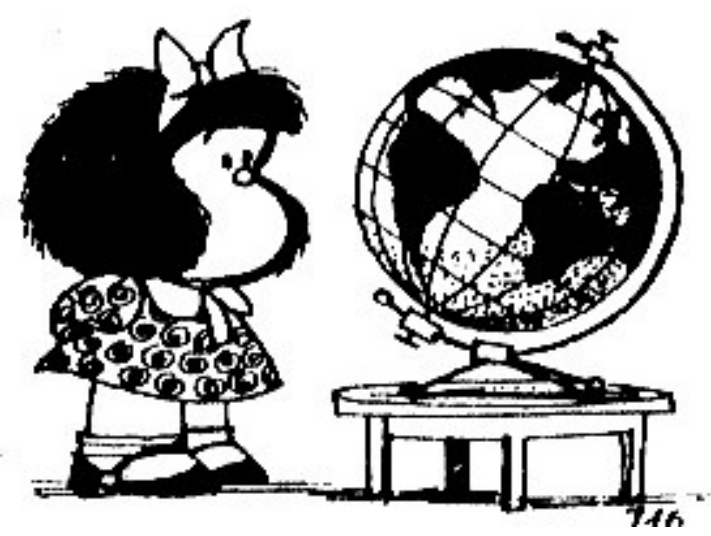

Fonte: http://geoprofessora.blogspot.com/2008/06/mafalda-e-geografia.html $^{5}$

Quando os portugueses chegaram ao Brasil havia de 6 a 10 milhões de índios e, aproximadamente, 1.300 línguas indígenas. Atualmente, quando do momento da escrita deste texto, a população indígena no país não chega a 817.963 mil, sendo composta por 305 etnias e contando com registro oficial de 74 línguas indígenas. Neste quantitativo, a maioria da população deste perfil encontra-se na faixa etária de 0 a 14 anos e está concentrada nas áreas rurais dos municípios, de acordo com os dados do Instituto Brasileiro de Geografia e Estatística - IBGE - (BRASIL, 1998/2010).

Especificamente o Estado de Mato Grosso do Sul, segundo o IBGE, como já mencionado, é a região em que se localiza a segunda maior população indígena do país, com 73.295 pessoas (BRASIL, 2010), informação esta que nos coloca em posição de destaque nacional tanto para a luta por práticas de promoção aos direitos, quanto, também, em termos de assistência e políticas educacionais que visem garantir a inclusão da criança no ambiente das instituições. Reportando-nos à realidade de Naviraí, município do interior do Estado, podemos afirmar que:

\footnotetext{
${ }^{4}$ Com financiamento da Pró-reitora de Extensão, Cultura e Esporte (PROECE) em parceria com a Fundação de Apoio à Pesquisa, ao Ensino e à Cultura (FAPEC), submetido pelo Edital PROECE/FAPEC nº 8, de 2 de março de 2018.

${ }^{5}$ Acesso em: 05, maio 2020.

SANTINO, Fernando Schlindwein; CIRÍACO, Klinger Teodoro. "O essencial é invisível aos olhos": percepções acerca da interculturalidade e etnomatemática no atendimento à infância indígena. Espaço Ameríndio, Porto Alegre, v. 15, n. 1, p. 113-133, jan./abr. 2021.
} 
No mapeamento inicial realizado em março do corrente ano, com vista à demanda social da inserção de crianças indígenas em creches e pré-escolas na sociedade naviraiense, contatou-se que, em 2018, existem aproximadamente 50 crianças frequentando os Centros Integrados de Educação Infantil local, número que tende a aumentar nos próximos meses (CIRÍACO, 2018, p. 104).

Face à tal realidade, podemos inferir que a inserção da criança indígena nas classes urbanas tem sido cada vez mais frequente e anuncia desafios aos profissionais da Educação Infantil, dentre os quais estamos incluindo a necessidade de uma postura de prática pedagógica na perspectiva da Interculturalidade.

O conceito de interculturalidade é central à (re)construção de um pensamento crítico - outro - um pensamento crítico de/desde outro modo, precisamente por três razões principais: primeiro porque está vivido e pensado desde a experiência vivida da colonialidade $[\ldots]$; segundo, porque reflete um pensamento não baseado nos legados eurocêntricos ou da modernidade e, em terceiro, porque tem sua origem no sul, dando assim uma volta à geopolítica dominante do conhecimento que tem tido seu centro no norte global (WALSH, 2005, p. 25).

Ao se relacionar tal reflexão com as vivências educacionais, especificamente com o espaço-tempo da Educação Infantil, podemos apontar que as professoras precisam conhecer, minimamente, a realidade vivida na/da infância indígena. Estamos entendendo, na leitura teórica e metodológica do contexto, que este torna-se pressuposto basilar a um trabalho docente que se quer fazer inclusivo, emancipatório e intercultural no sentido híbrido da questão. Consideramos o termo cultura híbrida, conceito que pode ser compreendido como o ato de romper barreiras que separam as culturas ditas tradicionais daquilo que é considerado moderno, por exemplo, a cultura indígena da cultura do homem que vive no meio urbano.

O ambiente educacional é considerado, neste entendimento, local favorável à promoção desta, pois é na instituição de ensino que ocorre a miscigenação ${ }^{6}$ entre culturas diferentes e será o professor de Educação Infantil o profissional responsável por essa mediação como processo comum do ser humano, portanto, a urgência de se apropriar de referenciais teóricos deste campo fora objeto da ação promovida pela UFMS no curso de extensão que se constitui o lócus desta experiência/investigação.

Autores como Canclini (1997, p. 284-285) definem a hibridação cultural como "processos socioculturais nos quais estruturas ou práticas

\footnotetext{
${ }^{6}$ A miscigenação ou mestiçagem consiste na mistura de raças de povos e de diferentes etnias. 
discretas, que existiam de forma separada, se combinam para gerar novas estruturas, objetos e práticas".

Eble e Lamar (2015, p. 202), em estudos de Canclini (1997), quando referem-se à cultura híbrida, afirmam que esta passa por três momentos:

o primeiro é a queda dos grandes centros disseminadores de cultura, pois, com essa variedade cultural crescente no mundo, não há mais um grande centro que transmita a cultura e que a emita de forma homogênea, provocando, assim, uma pluralidade de culturas e quebrando o padrão antigo da sociedade; o segundo é a disseminação de gêneros impuros, como, por exemplo, os ritmos musicais; diversos ritmos se misturaram com o tempo e se espalharam, criando uma variação nova de ritmos ao redor do globo, o mesmo podendo ser visto na cultura, ou seja, a mistura de costumes causou uma disseminação de gêneros misturados, causando uma variação cultural muito rica; o terceiro é a desterritorialização, no qual o território é espaço de desordem, de fragmentação para buscar encontrar novos saberes, menos instituídos, e se constituiu em um processo fundamental para que ocorresse o processo de globalização das culturas, pois a partir daí as culturas se misturariam e ganhariam características umas das outras.

Em um ambiente de cultura híbrida, a Interculturalidade ganha espaço, forma, corpo e conteúdo na docência e nas relações humanas que fazem/permitem o ensino e a aprendizagem de conceitos na creche e na pré-escola. Tais pressupostos são fundamentais para que a criança indígena passe pelo processo educacional e reconheça a participação de sua cultura na construção do conhecimento, bem como reconheça sua identidade étnica.

Quando nos propomos a falar da infância indígena precisamos ter clareza de que estamos entrando num universo extremamente complexo, pois trata-se de um contexto multiétnico e composto de uma enorme diversidade cultural. Quando falamos em índios, precisamos estar cientes de que existe uma grande diversidade de povos, cada qual com sua cultura, seus costumes, suas crenças, modos de viver e de conceber o mundo. Essa diversidade nos impõe a necessidade de desconstruir a ideia do índio que encontra-se generalizada no imaginário da população brasileira, a fim de eliminar equívocos de que "índio é tudo igual" (ZOIA; PERIPOLLI, 2010, p. 11).

"O índio passa pelo processo educacional e não é mais índio... e tampouco branco. Sem dúvida a elevada ocorrência de suicídio entre as populações indígenas está associada a isso" (D’AMBROSIO, 2013, p.76). Percebemos que o sistema educacional brasileiro está formatando as crianças, criando padrões por ele impostos - etnocentrismo - e, com essa 
triste realidade, as crianças indígenas estão sendo inferiorizadas pelos rituais dos não-indígenas, causando várias consequências, dentre elas a evasão escolar, dificuldade na aprendizagem e, nos casos mais extremos, o suicídio.

A figura docente representa um ator social importante no cenário de valorização e respeito às diferenças e para a garantia dos Direitos Humanos, sociais e culturais das crianças. Reconhecer a presença das diferentes culturas, desde a Educação Infantil, aponta para um olhar mais apurado à forma como o ensino e as áreas do conhecimento científico, dentre os quais a Matemática faz parte, são pensados e legitimados na vida em sociedade. Este espaço abre margem à Etnomatemática na cultura indígena.

A Etnomatemática vem demonstrando a sua importância no campo teórico e prático. D'Ambrósio (2013. p. 2) assim a define:

Etno, se refere ao contexto cultural do indivíduo, incluindo a linguagem e comportamentos; matema tem relação com explicar, conhecer; tica tem relação com a arte de técnica. Ficando assim, Etnomatemática: arte ou técnica de ensinar, explicar, conhecer e entender, nos diversos contextos culturais.

Conforme a definição posta pelo autor, considerado no mundo o pai da Etnomatemática, esta surge como conceito na tentativa de demarcar a existência de outras Matemáticas, para além da acadêmica-formal na lógica abstrata dos processos mentais, ou seja, apresenta-se como possibilidade de fazer ecoar a voz dos povos culturais subalternizados socialmente, podendo dar a eles a oportunidade de relatar de que forma utilizam a Matemática no cotidiano das ações diárias e de seus modos de produção de vida em sociedade, como fazem Matemática. Neste estudo, especificamente, citando sobre os povos indígenas (a criança indígena), seria importante que o professor conhecesse como as questões de natureza matemática se apresentam na infância, nas interações, nas brincadeiras, no auxílio das atividades familiares, entre outros aspectos, os quais somados poderiam resultar num saldo positivo à cultura matemática no ambiente da Educação Infantil.

Seguindo essa linha de raciocínio, torna-se, então, também relevante ao docente compreender os itinerários da intersecção entre 0 conhecimento matemático escolar e a relação dos modos de produção da Matemática na vida de determinadas culturas - dentre as quais as indígenas, lócus do assunto em questão. Assim, o professor poderia ensinar às crianças a respeitar as diferentes culturas e, como fruto disso, seria possível diminuir a discriminação étnica.

Em defesa de tal ação, Medeiros (2005, p.15) afirma que "ao romper com a ideia de uma única ordem Matemática e instaurar outras maneiras de operar com a matemática, a Etnomatemática preocupa-se em problematizar o mito da universalidade desta Matemática". Em concordância com os estudos de Medeiros (2005) e D'Ambrósio (2013), agora no sentido de relacionar o termo com a prática docente, Silva, Souza 
e Queiroga (2009, p.17) citam que "a visão Etnomatemática no campo educacional considera o professor para promover processo de ensino e aprendizagem" o que, sem dúvida, o coloca como mediador da aprendizagem de conceitos, "deixando de ser um mero transmissor ou informador de conhecimento, assim o mesmo ajudará no processo de ensino aprendizagem interagindo os conhecimentos escolares com os conhecimentos não escolares" (SILVA; SOUZA; QUEIROGA, 2009, p. 17).

Nessa perspectiva, o professor precisará ter conhecimento de quem são essas crianças e as suas origens, o seu cotidiano, quais as suas dificuldades. Assim, uma metodologia que pode funcionar seria a adoção de atividades que façam com que as crianças consigam conectar conteúdos matemáticos vivenciados na interação entre elas, evitando que fiquem isoladas. Este trabalho poderia vir a ocorrer por meio de uma abordagem dos conteúdos matemáticos pelo viés da Etnomatemática, por exemplo.

Para que tal pressuposto ocorra, seria interessante que o docente estivesse ciente do quão relevante são os conteúdos que irá problematizar/ensinar e quais possibilidades de uma prática pedagógica diferenciada que se preocupa com a Interculturalidade e os processos de associação destes com a questão da cultura indígena, especificamente. Acreditamos que ao se trabalhar na perspectiva da Etnomatemática, desde a Educação Infantil, as crianças irão se desenvolver em relação à Matemática de maneira mais positiva, pois estarão percebendo onde e como o desenvolvimento de alguns conceitos estão atrelados em suas atividades cotidianas à cultura e à cultura do outro, em um movimento de hibridização necessário ao início do processo de desenvolvimento e, consequente, da aprendizagem.

\section{Delineamento metodológico}

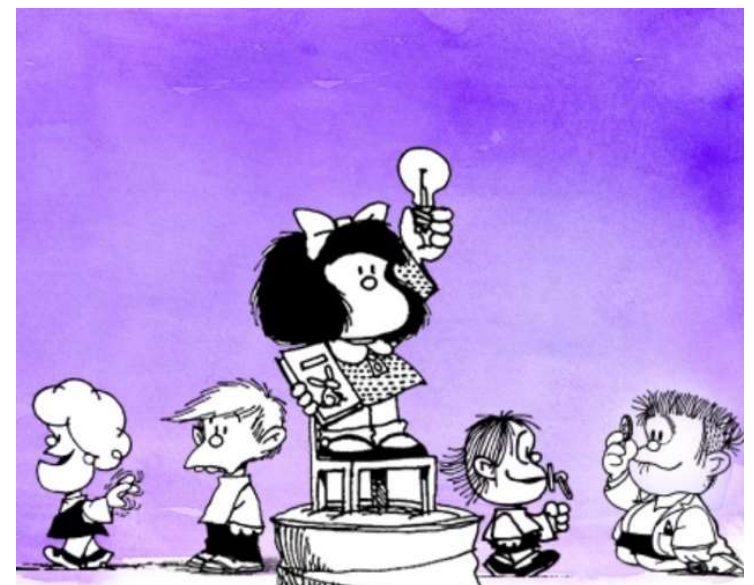

Fonte: https://brasil.elpais.com/brasil/2018/12/28/cultura/1546019502_949886.html. ${ }^{7}$

No âmbito da ação de extensão, cujos dados das percepções das professoras estão aqui estruturados, tínhamos como objetivo geral promover ações de intervenção, junto à rede municipal de Educação

\footnotetext{
${ }^{7}$ Acesso em: 15, maio 2020.
}

SANTINO, Fernando Schlindwein; CIRÍACO, Klinger Teodoro. "O essencial é invisível aos olhos": percepções acerca da interculturalidade e etnomatemática no atendimento à infância indígena. Espaço Ameríndio, Porto Alegre, v. 15, n. 1, p. 113-133, jan./abr. 2021. 
Infantil de Naviraí, na perspectiva de uma formação continuada, visando contribuir com as necessidades do atendimento à criança indígena inserida nos espaços das instituições com base em práticas curriculares que promovessem a Interculturalidade em um diálogo com a Etnomatemática na infância.

Para iniciar o curso de extensão, foi formado o grupo colaborativo do qual fizemos parte. Em seguida, elaboramos o cronograma de atividades que foi submetido à Fundação de Apoio à Pesquisa, ao Ensino e à Cultura (FAPEC), Edital PROECE/FAPEC n 8, de 2 de março de 2018 . Com a aprovação, obtivemos custeio de bolsas de extensão e materiais de consumo junto à Pró-Reitoria de Extensão, Cultura e Esporte (PROECE). Na sequência, organizamos reuniões quinzenais, aos sábados, nas dependências da UFMS - Campus Naviraí - de março a dezembro de 2018. As reuniões objetivaram identificar as práticas de ensino e aprendizagem das professoras, pensando em um movimento de reflexão-ação-reflexão com base no estudo coletivo dos conceitos de Interculturalidade e Etnomatemática a partir de oficinas com professores-pesquisadores renomados nas áreas temáticas do projeto: Profa. Dra. Adir Casaro Nascimento (Universidade Católica Dom Bosco - UCDB); Prof. Dr. Antonio Hilario Aguilera Urquiza (Universidade Federal de Mato Grosso do Sul UFMS/Campo Grande); Profa. Dra. Ilma Regina Castro Saramago de Souza (Universidade Federal da Grande Dourados - UFGD); Profa. Msc. Maria Aparecida Mendes de Oliveira (Universidade Federal da Grande Dourados - UFGD); e Prof. Dr. Thiago Donda Rodrigues (Universidade Federal de Mato Grosso do Sul - UFMS/Paranaíba).

No que diz respeito ao público-alvo, em média, 24 pessoas participaram da ação extensionista, dentre as quais destacam-se (15) professoras da rede municipal e (9) acadêmicos dos cursos de licenciatura em Ciências Sociais e Pedagogia. Em termos percentuais, respectivamente: $62,5 \%$ docentes e $37,5 \%$ futuros professores. A organização e dinâmica formativa, em termos práticos, transcorreu com base nas sessões reflexivas das oficinas com os especialistas nos assuntos abordados, sendo questões sobre: A criança e a infância indígena; Direitos e história dos povos indígenas em Mato Grosso do Sul; Etnomatemática; Estudos sobre a língua português-guarani e o currículo intercultural.

A seleção e disposição dos temas debatidos nestes encontros foi possível com base na categorização, análise e levantamento das dificuldades do grupo de extensionistas, dados estes coligidos a partir do desenvolvimento de um questionário diagnóstico aplicado no primeiro dia do curso. As perguntas que compuseram este instrumento de produção de dados contemplaram em três conjuntos de questões: 1) concepções de infância; 2) ensino de Matemática na perspectiva da Etnomatemática; e 3) relação das práticas pedagógicas no contexto da interculturalidade. Neste artigo, nos deteremos ao conjunto 2) ensino de Matemática na perspectiva da Etnomatemática.

Cumpre salientar que, em termos de pesquisa, o trabalho foi realizado na perspectiva dos estudos qualitativos em educação, haja vista que nesta abordagem o pesquisador está em contato direto com a situação investigada, bem como trata de forma detalhada e discute significados e 
sentidos atribuídos ao que se vive. Concordamos com Bogdan e Biklen (1994, p.195) ao afirmarem que:
embora os dados quantitativos recolhidos por outras pessoas (avaliadores, administradores e outros investigadores) possam ser convencionalmente úteis tal como foram descritos, os investigadores qualitativos dispõem-se à recolha de dados quantitativos de forma crítica. Não é que os números por si não tenham valor. Em vez disso, o investigador qualitativo tende a virar o processo de compilação na sua cabeça perguntando-se o que os números dizem acerca das suposições das pessoas que os usam e os compilam. [...] Os investigadores qualitativos são inflexíveis em não tomar os dados quantitativos por seu valor facial.

$\mathrm{Na}$ tentativa de ir além do valor facial expresso pelos autores, o questionário aplicado teve perguntas abertas e fechadas. Seu objetivo foi levantar as percepções das cursistas sobre a temática e identificar as dificuldades decorrentes do trabalho didático-pedagógico para organização dos moldes operantes da atividade de formação. A leitura e categorização das respostas foram experiências que possibilitaram redirecionar o planejamento do curso com vista à atingir os objetivos inicialmente propostos.

\section{Resultados e discussão}

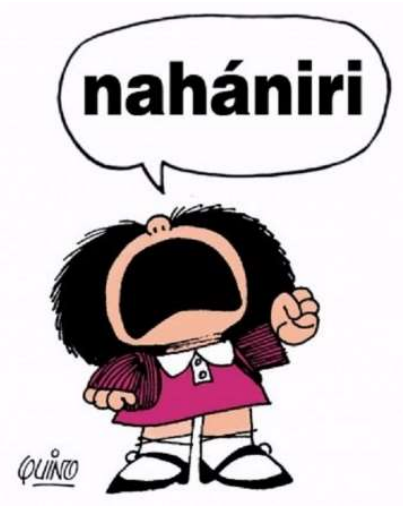

Fonte: https://operamundi.uol.com.br/politica-e-economia/47340/mafalda-do-cartunista-quinoganha-traducao-para-idioma-indigena-guarani-no-paraguai. ${ }^{8}$

A imagem que abre a seção desta parte do trabalho faz referência à notícia Mafalda aprende a falar em Guarani, $<$ https://vermelho.org.br/2017/05/29/mafalda-aprende-a-falar-emguarani/>, do jornal online "VERMELHO - A esquerda bem informada", datada de 29/05/2017. Tratava-se, naquele momento, de um projeto, em desenvolvimento, por linguistas paraguaios que visava traduzir a obra com

\footnotetext{
${ }^{8}$ Acesso em: 05, maio 2020.

${ }^{9}$ Para saber mais: https://vermelho.org.br/.

SANTINO, Fernando Schlindwein; CIRÍACO, Klinger Teodoro. "O essencial é invisível aos olhos": percepções acerca da interculturalidade e etnomatemática no atendimento à infância indígena. Espaço Ameríndio, Porto Alegre, v. 15, n. 1, p. 113-133, jan./abr. 2021.
} 
as aventuras da garotinha, no sentido de expandir sua história para outras culturas. Segundo o jornal, para a tradutora Maria Gloria Pereira, "a adaptação da obra de Quino servirá para fortalecer o idioma indígena e pode ser o começo de uma série de traduções de quadrinhos para popularizar e impulsionar o interesse infantil pela cultura guarani" (VERMELHO, 2017, p. 1).

Nahániri, traduzido para a Língua Portuguesa como não, empresta à Mafalda, na língua Guarani, o que queremos dizer no tempo presente: Nahániri! Chega! Basta! Não podemos mais aceitar processos de exclusão social das culturas étnicas que divergem dos processos colonizadores pelos quais passamos ao longo da história e que chegam, também, às instituições de ensino ameaçando, como no caso pesquisado, que crianças indígenas não aprendam Matemática, por exemplo, por problemas de comunicação com as professoras por falarem em suas línguas nativas. Nahániri!

Logo no primeiro encontro com o grupo de professoras da Educação Infantil, por meio das respostas do questionário, obtivemos informações importantes que retrataram a realidade do viver a infância indígena no contexto urbano. Evidenciou-se, em suma, nas percepções das docentes, que as crianças indígenas preferem ficar isoladas das demais crianças [crianças não-indígenas], demonstrando dificuldade de relacionamento e aprendizagem, e expressam reações comportamentais diferentes das crianças do contexto urbano como, por exemplo, não participar das atividades propostas, não brincar com os demais colegas e nem interagir com o outro.

Ao analisarmos a pergunta: Em sua percepção, na rede municipal existem práticas envolvendo a pluralidade cultural nas Instituições de Educação Infantil? Chegamos ao resultado:

Gráfico 1 - Existência de prática pluricultural nas instituições.

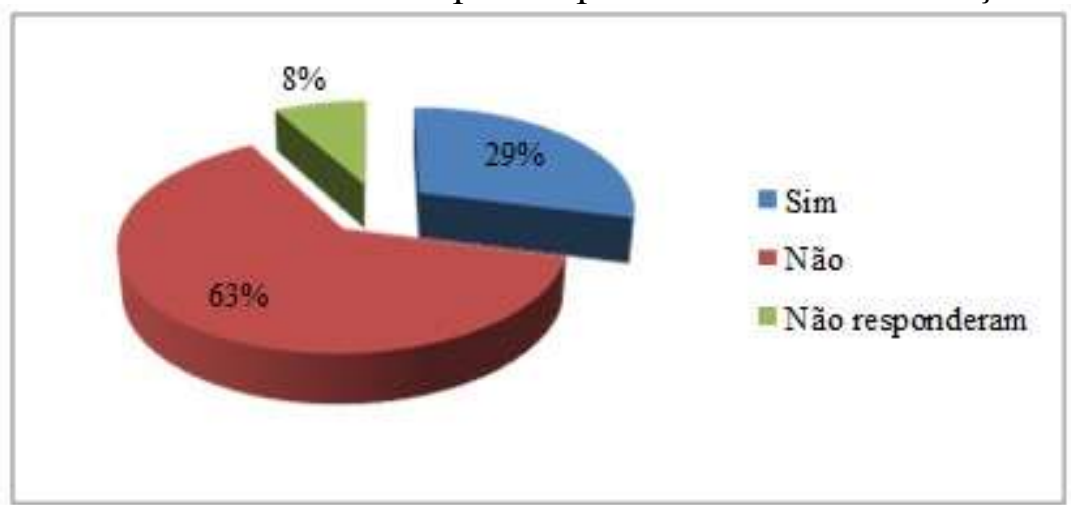

Fonte: Os autores, 2018.

Compreendemos por práticas de pluralidade cultural aquelas que envolvem ações que dizem respeito ao conhecer e valorizar "características étnicas e culturais dos diferentes grupos sociais que convivem no território nacional, as desigualdades socioeconômicas e a crítica às relações sociais discriminatórias e excludentes que permeiam a sociedade brasileira" (BRASIL, 1997, p. 121), as quais implicariam ações de formação na rede municipal, no sentido de instrumentalização das práticas docentes para 
que as professoras pudessem, no desenvolver da docência, ofertar às crianças "a possibilidade de conhecer o Brasil como um país complexo, multifacetado e algumas vezes paradoxal" (IDEM, p. 121).

Para iniciar o diálogo sobre a criança indígena, pensamos ser relevante que as professoras tivessem oportunidade de conhecer mais acerca da cultura dos povos originários (SOUZA; DRIGO; SILVA, 2015) para que pudessem problematizar e discutir tais aspectos nas vivências propostas ao grupo que atuam. Nesta direção, de reconhecimento e valorização da cultura indígena na infância, é fundamental o princípio da alteridade (colocar-se no lugar do outro e respeitar suas singularidades e diferenças) para que as crianças convivam em harmonia na perspectiva de formação de uma sociedade justa e democrática. Conhecer quem é a criança e suas características faz parte da pluralidade cultural:

estudar uma sociedade sem estudar a criança dessa sociedade resulta um estudo incompleto. A criança vive e se expressa dentro de limites e até amplitudes que Ihe são próprias, que tem zonas de intersecção com os limites e amplitudes do adulto com o qual convive. A criança não é uma versão reduzida do adulto nem este é uma versão ampliada da criança (NUNES, 2002, p. 275-276).

Destacamos que o município em que este estudo fora subsidiado, ao que tudo indica, parece não ter estudado quem são as crianças indígenas matriculadas na rede. Para nós, esta seria a base para implementação de práticas de pluralidade cultural, nas quais conhecer as etnias é pressuposto central para implementação de uma proposta pedagógica inclusiva que transcorra de modo híbrido/intercultural, dado que corrobora as orientações do Referencial Curricular Nacional para a Escola Indígena (RCNEI):

a possibilidade de vivência da pluralidade cultural sob o ponto de vista da aceitação; o reconhecimento não discriminatório das diferenças de etnia; a percepção do preconceito de classes sociais e da discriminação por gênero; a relação com o meio ambiente; a luta pelos direitos dos povos indígenas e de outros povos do mundo (BRASIL, 1998, 58).

$\mathrm{Na}$ apreciação crítica entre a teoria e as percepções iniciais das educadoras, destacamos, com base no gráfico 1 , que as instituições de Educação Infantil locais não estão reconhecendo as diferenças étnicas. Desse modo, 63\% das professoras estão conscientes de que não existem práticas que incluam as diferentes culturas existentes em sala de aula, fato que nos chama a atenção tendo em vista as orientações do RCNEI, em consonância com o Art. 29 da Lei de Diretrizes e Bases (LDB) 9.394 de 20 de dezembro de 1996, que ressalta o papel da Educação Infantil para e com todas as crianças: "A educação infantil, primeira etapa da educação básica, tem como finalidade o desenvolvimento integral da criança até seis 
anos de idade, em seus aspectos físico, psicológico, intelectual e social, completando a ação da família e da comunidade".

Com base nas respostas das professoras, realizamos a seguinte reflexão: se a maior parte delas tem consciência de que não existem práticas pluriculturais, algo poderia e deveria ser feito, uma vez que a assertiva posta em evidência denuncia a fragilidade da rede municipal para abordagem de questões ligadas à cultura indígena e, consequentemente, ao trabalho pedagógico com as crianças. A presente constatação valida estudos propositivos, como o que desenvolvemos, para que medidas sejam adotadas pelo poder municipal, estadual e/ou federal.

Frente à necessidade de implementação de políticas públicas que incentivem a Interculturalidade na perspectiva da Etnomatemática, uma vez que entendemos que não é responsabilidade única do professorado elaborar/recriar sozinho o ambiente para que as crianças indígenas tenham experiências com outras crianças, compreendemos que a formação continuada, neste caso, tem um papel primordial, razão pela qual visamos, no projeto de extensão, atender as necessidades formativas do grupo. Quando os professores ampliam seus repertórios de atuação, é possível contribuir com a propositura de vivências lúdico-exploratórias ao se tomar por base as práticas culturais parecidas/similares com as da aldeia, como apontam os estudos de Venere e Velanga (2008, p. 05), "as crianças aprendem brincando, imitando os mais velhos, participando da tradição oral, das atividades do dia-a-dia e dos rituais inerentes a cada cultura, aprendendo assim as regras do convívio social".

Ao verificar esses dados expostos, nós reformulamos o percurso da ação extensionista para que objetivasse, também, propor mudanças culturais das professoras, para que elas passassem a utilizar práticas pluriculturais, interculturais e a Etnomatemática, ou seja, práticas que colaborassem para a valorização e respeito do outro, das diferentes formas de ver/entender, principalmente quando o outro pertence a uma cultura subalternizada pela sociedade.

Notamos que essa realidade demonstra a falta de incentivo da gestão educacional e escolar, de políticas públicas que possibilitem a mudança de práticas - de preferência que envolvam a Interculturalidade e Etnomatemática - dos responsáveis por uma educação de qualidade.

$\mathrm{Na}$ análise de outra questão, a qual se referia à dificuldade de alfabetizar as crianças indígenas na linguagem matemática, percebemos que a maioria das cursistas afirmaram/sinalizaram positivamente para sim, demarcando, com isso, a falta de preparo para adotar práticas em que a abordagem de noções matemáticas com a cultura indígena seja recorrente. Tal dado deve-se a fatores de origens distintas, que podem ter influência, contemplando desde a falta de conhecimento da cultura deste público-alvo até a estruturação de uma prática docente pautada por perspectivas que estão além da cultura urbana. Em resposta, em termos de porcentagem, o índice revelou que 58\% das cursistas afirmaram ter dificuldades em trabalhar Matemática com a criança, percentual que evidencia a necessidade de se conhecer mais acerca da cultura indígena, como também a ampliação do repertório-didático pedagógico das 
professoras em relação a temas que abarquem tarefas interculturais na perspectiva da Etnomatemática.

Outro ponto que chamou a atenção foi as justificativas formuladas por quatro professoras que nos permitiram elaborar as seguintes categorias de respostas: a Educação Infantil contém poucas atividades de Matemática; falta relacionar o que se propõe com a realidade da criança; a dificuldade reside na aprendizagem, ou seja, a criança que tem limites; e a linguagem em geral é uma dificuldade na expressão, impossibilita o professor de sanar as dúvidas e auxiliar seus alunos.

A partir das categorias de respostas, podemos inferir que falta reorganizar o currículo para que as propostas de exploração da Educação Matemática na Educação Infantil possuam maior quantidade/qualidade e façam sentido ao grupo. As docentes relataram também a dificuldade em relacionar os conteúdos matemáticos com a realidade dos indígenas talvez seja pela falta de compreensão da língua materna (Língua Portuguesa) cristalizada pelos professores como sendo a predominante no meio urbano, sem perceber que a linguagem materna do índio é outra, o Guarani $^{10}$, e que esta precisa ser respeitada [no momento está sendo silenciada, mesmo inconscientemente]; neste pensamento fica evidente a impossibilidade de aquisição dos conteúdos matemáticos sem uma articulação destes com os modos de produção de vida dos sujeitos, o que nos aproxima, como já mencionado, das possibilidades que a Etnomatemática poderá trazer ao trabalho docente neste contexto.

Assim, constatamos que devemos superar essas dificuldades e criar a capacidade de conectar o conteúdo com a realidade da criança indígena. Isso é de suma importância visto que:

propiciar situações de cuidados, brincadeiras e
aprendizagens orientadas de forma integrada e que
possam contribuir para o desenvolvimento das
capacidades infantis de relação interpessoal, de ser e
estar com os outros em uma atitude básica de aceitação,
respeito e confiança, e o acesso, pelas crianças, aos
conhecimentos mais amplos da realidade social e cultural
(BRASIL, 1998. p. 23).

Por isso, os professores podem/devem encontrar formas de propiciar a valorização das crianças pelas suas origens, sejam elas indígenas, afrodescendentes, ribeirinhas, entre outras. A título de exemplificação, a professora, junto com a instituição de Educação Infantil, pode chamar um indígena adulto (podendo ser um pai ou mãe, por exemplo) para contar a história de sua vida, como ele sobrevive na cidade e/ou aldeia, contar para as crianças mais sobre a sua cultura, crenças, valores, culinária e, principalmente, sobre o idioma [guarani], comunicando-se com as crianças indígenas presentes. Tal ação vai ao

\footnotetext{
${ }^{10} \mathrm{O}$ idioma guarani é falado por, aproximadamente, 100.000 pessoas em três dialetos aparentados; GuaraniNandeva, Guarani-Kaiowá e Guarani-Mbya. O guarani é também a segunda língua oficial do Paraguai, tem material escrito, algumas gramáticas e dicionários. A maior parte das crianças indígenas em Naviraí - MS falam o Guarani-Kaiowá. 
encontro dos pressupostos sugeridos por Venere e Velanga (2008) e Barros (2015) ao estudarem a infância e as práticas interculturais de brincadeiras na educação indígena, respectivamente. Provavelmente, atividades desta natureza instigarão as demais crianças a dar valor e interagir mais com o outro, na tentativa de aprender algumas palavras em guarani, por exemplo.

Em outra questão, perguntamos: Professor/a, poderia me dizer qual sua visão/concepção sobre a criança indígena, quanto ao comportamento em sala de aula: A) Indiferente, elas sempre ficam em silêncio; B) São protagonistas do seu próprio conhecimento; C) Dificuldade no ensino/aprendizagem dos conteúdos matemáticos e da linguagem oral e escrita por eles falarem apenas o guarani; D) Interagem positivamente em relação ao conteúdo. Das respostas, o gráfico 2. ilustra as declarações:

Gráfico 2 - Dificuldades das professoras em alfabetizar na linguagem matemática.

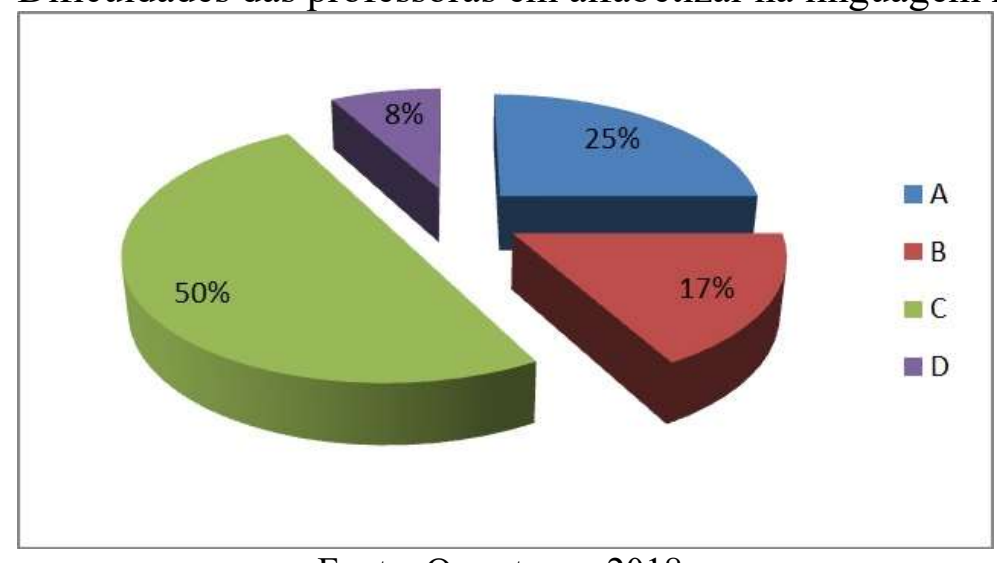

Fonte: Os autores, 2018.

Percebemos que $50 \%$ das professoras escolheram a alternativa: $C$ ) Dificuldade no ensino/aprendizagem dos conteúdos matemáticos e da linguagem oral e escrita por eles falarem apenas o guarani, dado que evidencia a língua como uma barreira sociocultural, segundo as professoras. A identificação da recorrente resposta, permite-nos indagar se crianças indígenas deveriam aprender a Língua Portuguesa ou as professoras a língua Guarani?

$\mathrm{Na}$ tentativa de refletir acerca da questão, uma afirmativa é certa, não queremos que a instituição de Educação Infantil se torne um leito de procusto $^{11}$. Ao contrário, o essencial da atividade educativa aqui parece estar, de fato, invisível aos olhos: a sensibilidade de se colocar no lugar da criança ao nos depararmos com a infância indígena [alteridade]. É preciso se vestir da "sensibilidade necessária, para com o olhar atento, captar e nos deixar seduzir pelas coisas mais simples do mundo; lançando um olhar infantil sobre a realidade indígena para vê-la com os olhos de uma criança" (ZOIA; PERIPOLLI, 2010, p. 11).

\footnotetext{
${ }^{11}$ Propomos como metáfora deste estudo fazendo uma comparação com a escola atualmente. Segundo a mitologia grega Procusto era um bandido que assaltava viajantes e os obrigava a se deitar em seu leito de ferro. Caso a vítima fosse maior que o leito, Procusto amputava o excesso de comprimento: se fosse menor, esticava. Veja mais em: https:/educacao.uol.com.br/disciplinas/filosofia/principios-e-dogmas-a-etica-e-oleito-de-procusto.htm?cmpid=copiaecola.
} 
Compreender que a língua não é um elemento dificultador, mas sim, algo que poderá ser potencializador, desde que conviva em coexistência com a língua falada no contexto urbano, poderia ser um caminho urgente e necessário ao grupo pesquisado, o que requer, em nosso entendimento, "formação continuada que atenda, de fato, reais necessidades" (SALGADO, 2018 , p. 96), que leve em consideração o bilinguismo aditivo ${ }^{12}$ uma vez que:

No Brasil, a imposição do português padrão não se refere somente à imposição de uma língua, mas, também, de uma única cultura e de uma única identidade, para todos. Estes três estão ligados de tal forma, que não há como caracterizá-las separadamente, isso porque uma língua está sempre ligada a uma cultura a qual representa que, por sua vez, contribui na formação de uma identidade, formação esta que ocorre por meio da língua, da interação com o "outro" (SILVA; TRISTONI, 2012, p. 236).

Assim, para que a formação de uma identidade [da criança] indígena se desenvolva sem processos de aculturação ${ }^{13}$ será necessário, além da formação consistente de professores com a práxis adequada ao currículo em uma perspectiva intercultural, é preciso que se incorporem metodologias que tenham como base - para o ensino da Matemática práticas Etnomatemáticas, valorizando e respeitando a cultura e língua do outro, fazendo com que a Educação Infantil se preocupe em compreender a cosmovisão, socialização primária e que se busque perceber quem é aquela criança da outra cultura, seus modos de brincar, agir e falar (VIEIRA, 2012).

Para além do percentual apresentado no gráfico 2., também nos chamaram a atenção as respostas que fizeram menção a: São tímidos, quietinhos no canto; interagem pouco, chegam à sala em silêncio; e devemos chamar mais de uma vez, chamar de forma individual. Na análise destas afirmações, podemos inferir que parece existir uma visão, mesmo que inconsciente, de que o problema da aprendizagem está no fato da criança ser indígena, o que para nós não representa uma verdade, pois todas as crianças têm potencialidades para se desenvolver e aprender Matemática, independentemente da cultura do sujeito. A questão central para as docentes que responderam o questionário residiria, dada à natureza de suas respostas, na dificuldade de aquisição da Língua Portuguesa pela criança indígena, o que representa para elas um desafio ao ensino de Matemática. É relevante destacar a falta de interação com as outras crianças, esse comentário da professora vai ao encontro do que relata Silva, Souza e Queiroga (2009, p. 29):

\footnotetext{
12 Bilinguismo aditivo: Usar a língua portuguesa e matemática para somar à língua materna e não para substituir (GRUPIONI, 2006, p. 22).

${ }^{13}$ Processo de modificação cultural de indivíduo, grupo ou povo que se adapta a outra cultura ou dela retira traços significativos.
} 
Constatamos então que este sujeito se encontra na escola, como um objeto manipulado sendo fabricado por concepções educacionais vistas como certas, através disso este sujeito torna-se oculto por não participar da construção do seu processo educativo. Este não critica nem questiona, aceita o que lhe é imposto.

Ao se caminhar para este lado, além de querer formar cidadão com um ensino padrão da cultura europeia, não estamos pensando em atividades significativas a serem propostas para a criança indígena. Isso quer dizer que a Educação Infantil não está cumprindo seus objetivos sendo que, dentre eles, encontra-se o de "dar continuidade à educação tradicional oferecida na família e articular-se às práticas socioculturais de educação e cuidado coletivos da comunidade" (BRASIL, 2010, p. 3). Se não tomarmos cuidado com isso, poderemos, mesmo que não explicitamente, acabar com a identidade étnica das crianças indígenas.

\section{Conclusões}
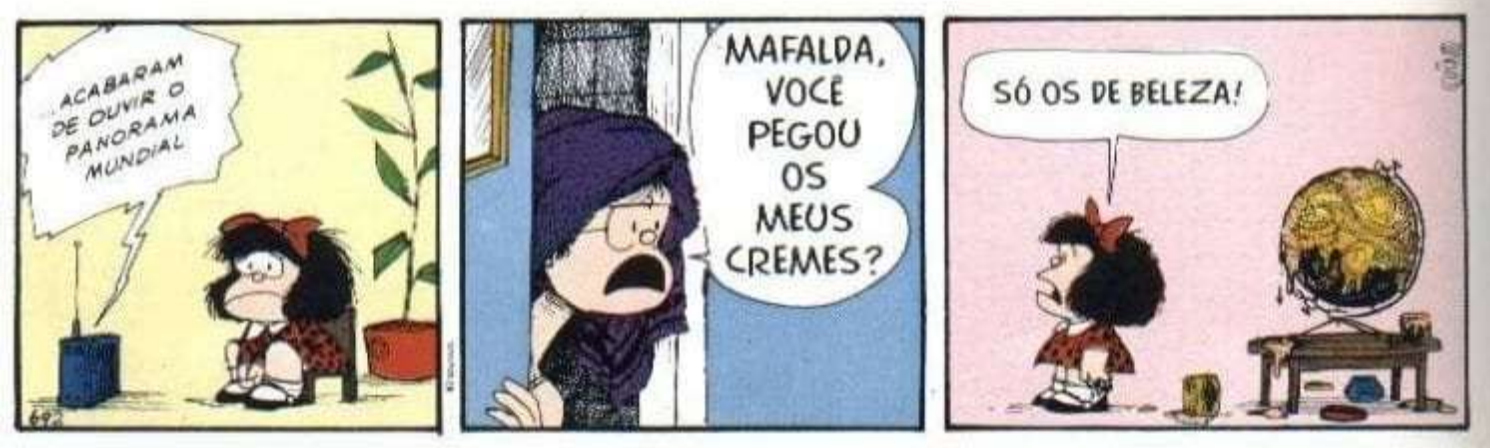

Fonte: https://segredosdomundo.r7.com/mafalda/ ${ }^{14}$

A tirinha de Mafalda expressa uma crítica ao panorama mundial, frente aos dados de um noticiário de rádio, em que, após saber como andam as coisas pelo mundo, para a garota, à primeira vista ingênua, a utopia de que os cremes de beleza de sua mãe poderiam contribuir para melhorar a imagem que globo terrestre nos apresenta, em uma leitura crítica e filosófica da imagem em questão, embelezar as formas de se ver e pensar os problemas de ordem social, econômica, política e, porque não dizer, histórica.

Ao reportarmos o processo de vivência, objeto de discussão neste artigo, podemos, em analogia à tirinha, destacar que, para nós, as formas de ver e pensar a criança indígena, bem como seu processo de aprendizagem matemática não poderão se embelezar com cosméticos, mas sim, com uma visão de mundo que transcenda e extrapole a supervalorização de uma cultura, apenas. É preciso a implementação de práticas que visem contribuir com a pluralidade cultural dos sujeitos, que deem visibilidade para a cultura indígena na sociedade não-índia. É hora

\footnotetext{
${ }^{14}$ Acesso em: 05, maio 2020.

SANTINO, Fernando Schlindwein; CIRÍACO, Klinger Teodoro. "O essencial é invisível aos olhos": percepções acerca da interculturalidade e etnomatemática no atendimento à infância indígena. Espaço Ameríndio, Porto Alegre, v. 15, n. 1, p. 113-133, jan./abr. 2021.
} 
de juntos dizermos: Nahániri [Não] ao preconceito, à subalternização, enfim, é momento de dar destaque e valorizar a singularidade das etnias no processo da pluralidade em que se encontram no Brasil.

Dadas as reflexões expressas, com base na análise dos dados expostos ao longo do presente trabalho, podemos inferir que, aparentemente, as professoras estão com dificuldades em ensinar as noções matemáticas para as crianças indígenas por vários fatores. Dentre estes, os que mais chamam atenção são: a linguagem, a dificuldade de interação professor-criança, criança-criança e a falta de tempo para tais atividades.

O estudo trouxe elementos importantes para compreender a percepção inicial do grupo e isso auxiliou na organização da ação formativa, de modo que passamos, ao longo do ano de 2018, a abordar aspectos declarados como fatores determinantes na aprendizagem matemática das crianças e dos modos de relação com a cultura indígena pelas docentes. O resultado disso foi a ampliação das discussões/debates, na perspectiva crítica dos sujeitos, possibilitando discussões sobre a Interculturalidade e dos princípios da Etnomatemática, principalmente, em Naviraí e região. Pensamos que este trabalho promoveu avanços tanto para área teórica como uma base para repensar as práticas que as professoras realizavam em sala de aula, corroborando vivências mais dinâmicas com respeito e interação com o outro, em consonância com o ensino-aprendizagem, valorizando a Matemática dos diferentes povos (Etnomatemática).

Em nosso entendimento, a Gerência Municipal de Educação e Cultura $^{15}$ (GEMED), juntamente com as instituições de ensino, podem/devem promover o incentivo à formação continuada e aos planejamentos e projetos visando o auxílio às crianças indígenas, com relação à alfabetização/alfabetização matemática. Paralelamente, também devem ser estimuladas a realização de leituras de textos que falem sobre a Interculturalidade e a Etnomatemática na Educação Infantil pelas professoras o que, sem dúvida, poderá elevar o grau de instrução para a constituição de práticas pedagógicas promotoras da valorização do outro como sendo o diferente e necessário para uma sociedade mais justa e igualitária, que respeita o direito do ser diferente como possibilidade de compartilhamento de experiências desde a infância.

Com base na experiência que vivenciamos na atividade de extensão realizada, sinalizamos a necessidade do incentivo para mais estudos sobre a temática indígena, tendo em vista a alta demanda de discussão sobre o tema, o número expressivo de crianças indígenas matriculadas nas instituições urbanas de ensino e a quase inexistência de estudos neste campo. Particularmente, acreditamos ser importante caracterizar e estudar a realidade local. Assim, práticas que tenham Naviraí, interior do Estado de Mato Grosso do Sul (MS), como objeto de reflexão são, para nós, fundamentais.

\footnotetext{
${ }^{15}$ Comumente conhecida por Secretaria Municipal de Educação, no entanto, em Naviraí-MS, tal setor intitula-se como Gerência Municipal de Educação e Cultura (GEMED). 
Espaço Ameríndio

\section{Referências bibliográficas}

BARROS, J. L. da C. O brincar e suas relações interculturais na escola indígena. $1^{\text {a }}$. ed. - Curitiba: Appris. 2015.

BOGDAN, R.; BIKLEN, S. K. Investigação qualitativa em educação: uma introdução à teoria e aos métodos. Porto, Porto Editora, 1994.

BRASIL, Conselho Nacional de Educação, Câmara de Educação Básica. Brasília (DF); 2010.Disponível

em:

http://portal.mec.gov.br/index.php?option $=$ com docman\&view $=$ download\&alias $=2296-$ cne-resolucao005-2009-pdf\&Itemid=30192. Acesso em: 05, ago. 2018.

BRASIL, Instituto Brasileiro de geografia e Estatística. Censo demográfico, 2010. Disponível em: http://www. censo2010. ibge. gov. br/. Acesso em: 15, abr. 2020.

BRASIL, Lei n. 9394, Lei de Diretrizes e Bases da Educação Nacional. De Educação Básica, São Paulo: Federação dos Professores do Estado de São Paulo, 1996. Disponível em: http://www.planalto.gov.br/ccivil 03/leis/19394.htm. Acesso em: 17, abr. 2020.

BRASIL, Ministério da Educação e do Desporto, Secretaria de Educação Fundamental. Referencial Curricular Nacional para a Educação Infantil. Brasília (DF); 1998. 1 v. Disponível em: http://portal.mec.gov.br/seb/arquivos/pdf/rcnei_voll.pdf> Acesso em: 05, ago. 2018.

BRASIL, Ministério da Educação e do Desporto, Secretaria de Educação Fundamental. Referencial Curricular Nacional para as Escolas Indígenas. Brasília: MEC/SEF, 1998. Disponível em: http://www.dominiopublico.gov.br/pesquisa/DetalheObraForm.do?select action=\&co o bra $=26700$. Acesso em: 13, jan. 2019.

BRASIL, Ministério da Educação e do Desporto. Parâmetros curriculares nacionais: pluralidade cultural. Secretaria de Educação. Fundamental. - Brasília: MEC/SEF, $1997 . \quad$ Disponível em: http://portal.mec.gov.br/seb/arquivos/pdf/pluralidade.pdf. Acesso em: 21, maio 2020.

CANCLINI, N. G. Culturas híbridas: estratégias para entrar e sair da modernidade. São Paulo: Edusp, 1997.

CIRÍACO, K. T. “Com quantos paus se faz uma canoa?”: Etnomatemática, interculturalidade e infância indígena na educação infantil urbana. Interfaces da Educação, v. 9, p. 101-127, 2018. Disponível em: https://periodicosonline.uems.br/index.php/interfaces/article/download/3122/2503. Acesso em: 04, jan. 2018.

D'AMBROSIO, U. Etnomatemática - elo entre as tradições e a modernidade. 5. Ed. Belo Horizonte: Autentica editora, 2013. 
EBLE, T. A; LAMAR, A. R. A literatura marginal/periférica: cultura híbrida, contrahegemônica e a identidade cultural periférica. Especiaria - Cadernos de Ciências Humanas. v. 16, n. 27, jul./dez. 2015, p. 193-212. Disponível em: http://periodicos.uesc.br/index.php/especiaria/article/view/1126/1005. Acesso em: 18, mar. 2019.

GRUPIONI, L. D. B. Formação de professores indígenas: repensando trajetórias. Brasília: Ministério da Educação, Secretaria de Educação Continuada, Alfabetização e Diversidade, $2006 . \quad$ Disponível em: http://pronacampo.mec.gov.br/images/pdf/bib_volume8 formacao de professores indig enas_repensando_trajetorias.pdf. Acesso em: 20, abr. 2020.

MEDEIROS, N. M. J. Narrativas sobre a "tradição" gaúcha e a confecção de bombachas: um estudo etnomatemático. Dissertação (Mestrado em Educação). Universidade do Vale do Rio dos Sinos, São Leopoldo, (RS) Brasil. 2005. Disponível em: http://www.repositorio.jesuita.org.br/handle/UNISINOS/1926. Acesso em: 04, ago. 2018. NUNES, Â. O lugar da criança nos estudos sobre sociedades indígenas. In: SILVA, A. L. da et al. (Orgs.). Crianças indígenas: ensaios antropológicos. São Paulo: Global, 2002.

SALGADO, D. F. da S. Saberes docentes sobre alfabetização em contexto de variedades linguísticas de Português/Espanhol. Dissertação (Mestrado em Ensino) Universidade Estadual do Oeste do Paraná, Campus de Foz do Iguaçu, 2018. Disponível em:

http://tede.unioeste.br/bitstream/tede/3690/5/Daniela_Fonseca_Siva_Salgado_2018.pdf.

Acesso em: 21, abr. 2020.

SILVA, E. C. F; SOUZA, R. de; QUEIROGA, V. S. Etnomatemática e prática de professoras na Educação Infantil. Governador Valadares, (MG) 2009. Disponível em: http://www.pergamum.univale.br/pergamum/tcc/Etnomatematicaepraticadeprofessorasna educacaoinfantil.pdf. Acesso em: 04, mar. 2019.

SILVA, G. M; TRISTONI, R. H. P. Diversidade cultural e linguística nas escolas de fronteira Brasil/Paraguai. Revista Travessias, v. 6, n.1, 2012. Disponível em: http://erevista.unioeste.br/index.php/travessias/article/view/6214/4846. Acesso em: 18, abr. 2020.

SOUZA, L. C. P. de; DRIGO, M. O.; SILVA, P. C. da. Alteridade e os povos originários do Brasil: um estudo com representações visuais em livros didáticos. Conexão Comunicação e Cultura, UCS, Caxias do Sul - v. 14, n. 28, jul./dez. 2015, p. 51-72. Disponível

em: http://www.ucs.br/etc/revistas/index.php/conexao/article/download/3275/2330. Acesso em: 15, mar. 2020.

VENERE, M. R; VELANGA, C. T. A criança indígena e a educação infantil: as complexas relações entre a cultura e a escola na cidade. Revista Tellus, UCDB, ano 8, n. 15, p. 175191, jul./dez. 2008. Disponível em: https://www.tellus.ucdb.br/tellus/article/view/167/199. Acesso em: 15, abr. 2020.

VERMELHO, A esquerda bem informada. "Mafalda aprende a falar em Guarani”. São Paulo. Notícia de 29/05/2017. Disponível em: 
https://vermelho.org.br/2017/05/29/mafalda-aprende-a-falar-em-guarani/. Acesso em: 21, maio 2020 .

VIEIRA, D. da S. Crianças indígenas na cidade: a Educação Infantil no Centro Social Mitangue-Nhiri. In: X Seminário de Ciências Sociais - Tecendo diálogos sobre a pesquisa social. Maringá: Universidade Estadual de Maringá - Departamento de Ciências Sociais. Anais..., $2012 . \quad$ p. $\quad 179-191 . \quad$ Disponível em: http://www.dcs.uem.br/xseminario/artigos resumos/gt2/x seminarios gt2-a3.pdf. Acesso em: 19, abr. 2020.

WALSH, C. Interculturalidad crítica y educación intercultural In: Construyendo Interculturalidad Crítica. III-CAB. Instituto Internacional de Integración del Convenio Andrés Bello. La Paz - Bolívia, 2010, 75-96. Disponível em: https://docplayer.es/13551165-Interculturalidad-critica-y-educacion-intercultural.html. Acesso em: 20, jun. 2019.

ZOIA, A.; PERIPOLLI, O. J. Infância indígena e outras infâncias. Espaço Ameríndio, Porto Alegre, v. 4, n. 2, p. 9-24, jul./dez. 2010. Disponível em: https://seer.ufrgs.br/EspacoAmerindio/article/view/12647/10473. Acesso em: 21, maio 2020 . 